\title{
Middle ear adenoma: Tumour of mixed mucinous and neuroendocrine differentiation
}

\author{
R J Hale, R F T McMahon, J S Whittaker
}

\begin{abstract}
Two cases of progressive hearing loss due to middle ear tumours are described. The histological characteristics numbered intraluminal mucin production and neuroendocrine features, as shown by agryrophilia and ultrastructural demonstration of dense core granules. These tumours have been known by many different names, reflecting the controversies relating to their presumed histogenesis and differentiation. The currently preferred designation is middle ear adenoma, and these two cases provide further evidence for dual lines of differentiation.
\end{abstract}

Middle ear adenoma was first described by Hyams and Michaels in $1976^{1}$ and since then over 50 cases have been reported. A total of 18 similar tumours have also been reported as carcinoid tumours of the middle ear. These tumours have excited considerable interest with regard to their histogenesis and differentiation and have been variously described as, or confused with, ceruminous adenoma, ceruminoma, adenomatous tumour, aural hidradenoma, monomorphic adenoma and low grade adenocarcinoma. In this study, we present our findings on two tumours of the middle ear which add further evidence for dual lines of differentiation in these unusual tumours.

\section{Case reports}

CASE 1

A 27 year old man presented with progressive hearing loss. At operation a firm tumour was found which was adherent to the intact tympanic membrane. Several small pieces were removed for pathological examination and the patient made an uneventful recovery. Histological examination showed an infiltrating tumour (with some crush artefact) which had a varied pattern including trabecular, glandular, and solid areas (fig 1). Mitoses were scanty and little nuclear plemorphism was seen. Alcianophilic mucin was identified in glandular lumina but no intracytoplasmic mucin was found. Many cells contained a moderate amount of granular eosinophilic cytoplasm. A high proportion of these cells showed argyrophilia with the Grimelius stain (fig 2), particularly prominent at the base of cells and acini, with scattered cells exhibiting immunoreactivity for chromogranin and neurone specific enolase. Electron microscopical examination showed the presence of typical neurosecretory granules (fig 3).

\section{CASE 2}

A 42 year old woman presented with a two year history of progressive hearing loss of mixed perceptive and conductive types. A tumour was noted in the middle ear, adjacent to the intact tympanic membrane, and excision biopsy was performed. A mastoid abscess developed, requiring antibiotics and drainage. The subsequent clinical course was uneventful and the patient remained well 19 years after presentation. Histologically, the tumour was composed of nests and cords of round/cuboidal cells which infiltrated a fibrotic stroma. There was little pleomorphism and few mitoses. Glandular lumina were noted which contained alcianophilic mucin, although no intracytoplasmic mucin was seen (fig 4). Many of the cells, particularly those at the base of acini, contained eosinophilic granular cytoplasm which were Grimelius

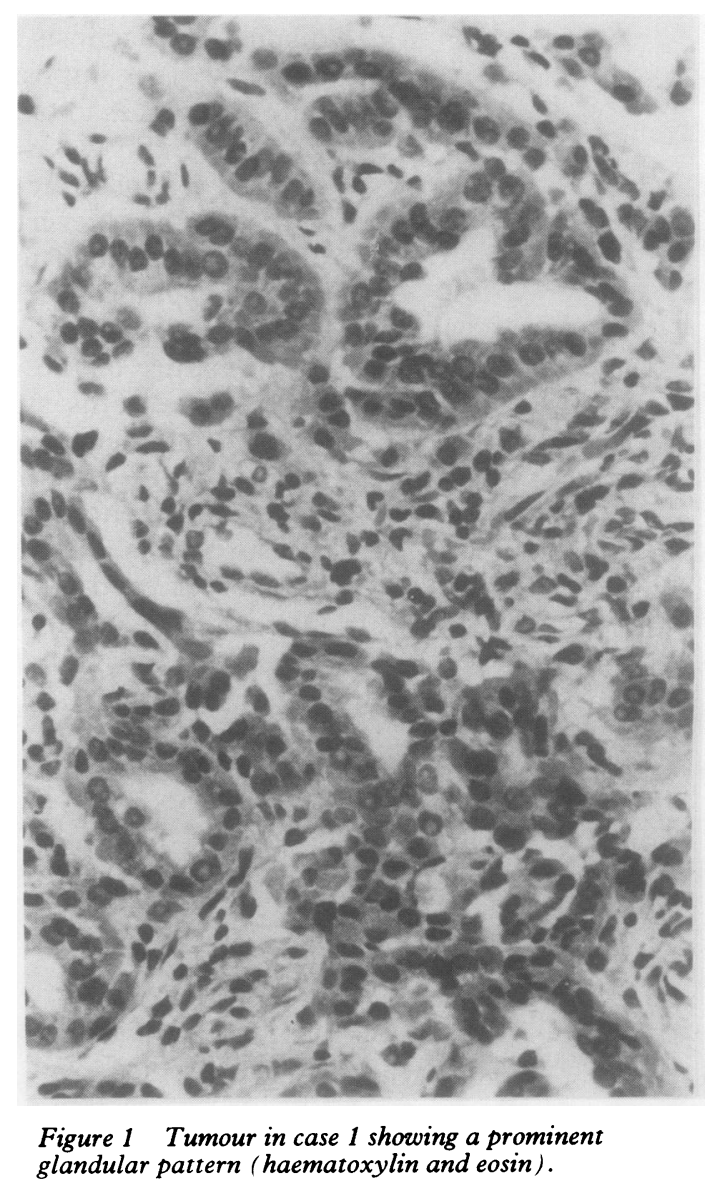

Department of
Histopathology,
Wythenshawe Hospital
R J Hale
J S Whittaker
Division of
Histopathology,
Department of
Pathological Sciences,
University of
Manchester
R F T McMahon
Correspondence to:
Dr R J Hale
Department of Pathology, St
Mary's Hospital, Hathersage
Road, Manchester, M13 0JH
Accepted for publication
20 February 1991


Figure 2 Case 1 displaying a positive Grimelius reaction, with noticeable granular staining particularly concentrated in the basal portions of cells at the periphery of acini. (Grimelius).

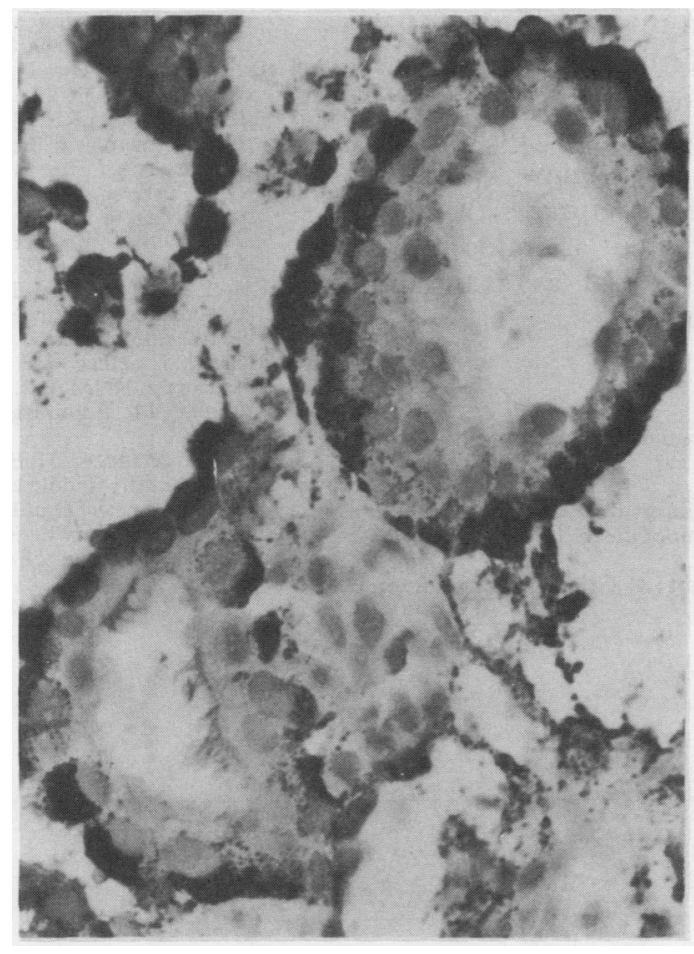

positive. Some of these cells were positive for neurone specific enolase and chromogranin on immunohistochemical staining. Only tissue extracted from the paraffin wax blocks was available for electron microscopy and this proved unhelpful.

\section{Discussion}

Primary tumours of the middle ear are unusual neoplasms and many different names have been applied to them. In 1976 Hyams and Michaels described the concept of middle ear adenomas ${ }^{1}$ and later Murphy et al reported the first instance of a carcinoid tumour of the middle ear. ${ }^{2}$ In fact, this latter group showed a combined mucinous and neuroendocrine neoplasm and subsequently, 18 more cases of such combined tumours were reported. ${ }^{3-7}$ In the meantime many cases of pure neuroendocrine tumours and pure adenomas were also described. This has led to the suggestion

Figure 3 An electron micrograph of case 1 showing a tumour cell containing neurosecretory granules (uranyl acetate lead citrate).

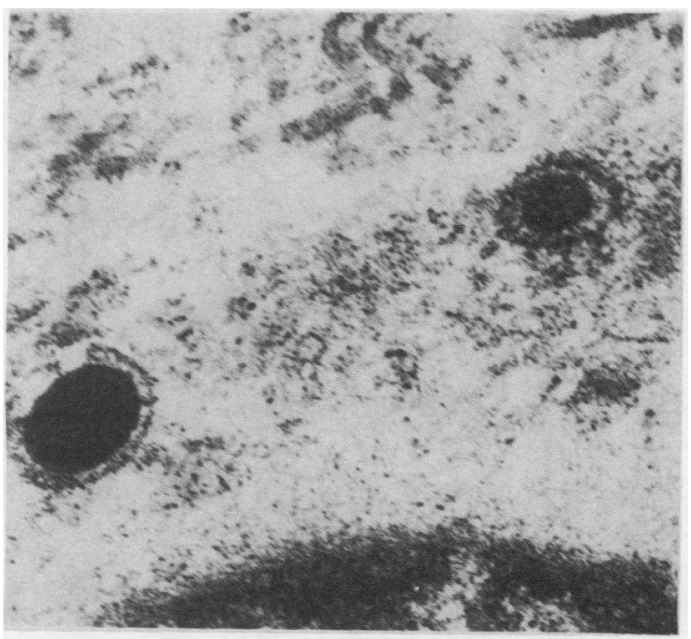

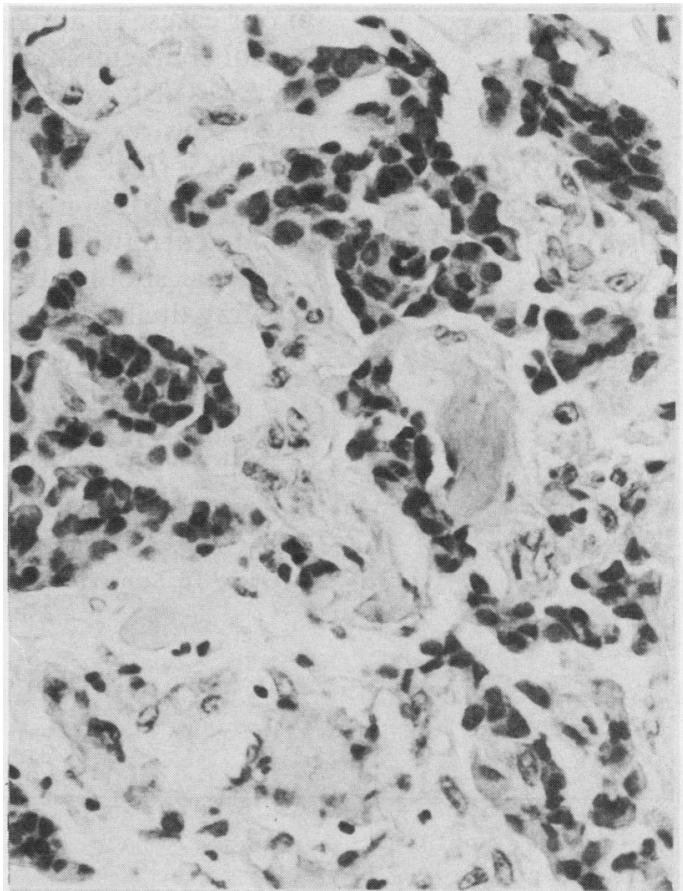

Figure 4 Trabecular and ribbon pattern in tumour of case 2 with focal glandular lumina (haematoxylin and eosin).

that adenomas and carcinoid tumours represent the ends of a spectrum of differentiation of such tumours. ${ }^{7}$ Thus it is not unexpected that combined tumours showing both mucinous and endocrine features would be recognised. Michaels, however, has argued against the use of the term "carcinoid" for these tumours because they do not display endocrine effects or behave aggressively. ${ }^{8}$ Recent reports suggest that this is not entirely correct. Latif et al described a single case with vague symptoms of palpitations and diarrhoea, which regressed on removal of the tumour and was thought to represent the systemic manifestations of carcinoid syndrome, although no definitive biochemical investigations were performed. ${ }^{9}$ Stanley et al, in one of their two cases, reported a case which recurred locally on two occasions. ${ }^{10}$ Carcinoid tumours at other sites may also lack some of these characteristic behavioural features and it is not unusual to find gastrointestinal and occasional bronchial tumours which also secrete mucin.

In this study we have shown unequivocal evidence of neuroendocrine differentiation by the demonstration of argyrophilia and neurone specific enolase and chromogranin positivity immunohistochemically. In one case typical neurosecretory granules were seen ultrastructurally. Intraluminal acidic mucin was identified although no intracytoplasmic mucin or mucin granules at electron microscopy could be found. Some previous reports have described both intracytoplasmic mucin and dense core granules in separate cells of the same tumour. In these cases the neurosecretory granules have been localised to the base of cells at the periphery of acini, and this is reflected in the pattern of argyrophilia seen 
in our cases. In addition to showing the histological characteristics of middle ear adenomas, our cases also confirm the more recently recognised features of neuroendocrine differentiation. We feel that there is now sufficient evidence to support the argument that the lesion currently designated as middle ear adenoma should be accepted as a tumour showing dual differentiation.

1 Hyams VJ, Michaels L. Benign adenomatous neoplasm (adenoma) of the middle ear. Clin Otolaryngol 1976;1: 17-26.

2 Murphy GF, Pilch BZ, Dickersin GR, Goodman ML, Nadal JB. Carcinoid tumour of the middle ear. Am J Clin Pathol 1980;73:816-23.

3 Davies JE, Semeraro D, Knight LC, Griffiths GJ. Middle ear neoplasms showing adenomatous and neuroendocrine components. $J$ Laryngol Otol 1989;103:404-7.

4 Kodama H, Takezawa H, Suzuki T, et al. Carcinoid tumour of the middle ear. J Laryngol Otol 1989;103:86-91.

5 Mills SE, Fechner RE. Middle ear adenoma-a cytologically uniform neoplasm displaying a variety of architectural patterns. Am J Surg Pathol 1984;8:677-85.

6 Ruck P, Pfisterer EM, Kaiserling E. Carcinoid tumour of the middle ear-a morphological and immunohistochemical study with comments on histogenesis and differential diagnosis. Path Res Pract 1989;185:496-503.

7 Wassef M, Kanavaros P, Polivka M, et al. Middle ear adenoma-a tumour displaying mucinous and neuroenadenoma-a tumour displaying mucinous and neuroen-

docrine differentiation. Am J Surg Pathol 1989;13:838-47.
8 Michaels L. Head and neck tumours. In: Antony PP, Michaels L. Head and neck tumours. In: Antony PP,
MacSween RNM, eds. Recent advances in histopathology. Volume 14. Edinburgh: Churchill Livingstone, 1989: $101-22$

9 Latif MA, Madders DJ, Barton RPE, Shaw PAV. Carcinoid tumour of the middle ear associated with systemic symptoms. J Laryngol Otol 1987;101:480-6.

10 Stanley MW, Horwitz CA, Levinson RM, Sibley RK. Carcinoid tumours of the middle ear. Am J Clin Patho 1987;87:592-600.

\section{Eponyms in pathology ...}

KLEBS, Theodor Albert Edwin (18341913) was a German microbiologist born in Konigsberg, Prussia, where he studied under Rathke and von Helmholtz after qualifying in medicine. In 1861 he became Virchow's assistant in Berlin, having been his pupil in Wurzburg for several years. He became professor of pathology in Berne, Switzerland, taking up Swiss citizenship while there, and later held chairs in Wurzburg, Prague (where he worked with Rokitansky), Zurich, and Karlsruhe. He then emigrated to North America where he was professor of pathology at Rush Medical College, Chicago, but returned to Europe in 1900 , working for five years in Hanover before moving to Berlin, Lausanne, and finally Berne again where he died at the age of 79 . A prolific worker and writer who made immense contributions to the then new science of bacteriology, he was an innovator who often left others to develop his original ideas and was therefore never the first to put his name to any of the important discoveries. Among other things, he established the importance of the intestinal route for the entry of tubercle bacilli, and he is credited, along with Loeffler, with the discovery of the diphtheria bacillus in 1893 (Klebs-Loeffler bacillus). The genus of Gram negative bacteria, Klebsiella, is named after him. 